\title{
Prevalence and Predictors of Pediculosis Capitis among Female Primary School Children in Kuantan, Pahang
}

Nur Aqilah Yunos, Nor Faiza Mohd Tohit, Razman Mohd Rus

Kulliyyah of Medicine, International Islamic University Malaysia

Presenter: Nur Aqilah Yunos

Introduction: Pediculosis capitis has been a worldwide concern among the vulnerable population of primary school children due to the physical, economical and psychological consequences that it brings to both the children and their caretakers. It is observed that there were only limited studies conducted in Malaysia and no previous study was done in Kuantan despite the health concern that it bears. Since both local and worldwide studies show that Pediculosis capitis is more prevalent among female as compared to male school children, thus, this study aims to investigate the prevalence and predictors of Pediculosis capitis among female primary school children in Kuantan. Materials and method: An analytical crosssectional study using cluster random sampling was carried out in Kuantan, Pahang, Malaysia. A self-administered validated questionnaire was used to collect the data among female primary school children from standard one to six. Hair and scalp examination was performed to identify presence of Pediculosis capitis infestation. Multivariate logistic regression was used to control for potential confounding and determine the predictors Results: 10 schools participated in the study with total number of 636 female students as respondents. The overall prevalence of Pediculosis capitis among female primary school children was $17.6 \% \quad(n=112)$. Multivariate logistic regression analysis showed that Indian $(\mathrm{OR}=5.634,95 \% \mathrm{Cl}=$ 3.157-10.055), history of contact with infested person (OR=2.822, 95\% Cl=1.619$3.691)$ and those who had number of family members more than four (OR=0.065, 95\% $\mathrm{Cl}=0.008-0.550)$ were predictors for Pediculosis capitis Conclusion: The prevalence of Pediculosis capitis among female primary school children in Kuantan, Pahang is endemic (17.6\%) and predictors are Indian, history of contact with infested person and having family members of more than 4. Hence, there is a need for health intervention to reduce the burden of Pediculosis capitis infestation. 